\section{NUEVAS VÍAS DE ADMINISTRACIÓN DE ALCOHOL EN ADOLESCENTES}

\section{NEW ROUTES OF ADMINISTRATION OF ALCOHOL IN TEENS}

\author{
Carlos Andrés Carrasco-Farfán 1,2,a , \\ Cesar Miguel Quispe-Nolazco 1,2,a, \\ Javier Antonio Quispe-Nolazco ${ }^{1, a}$, \\ Lily Ávalos-Moreyra ${ }^{1, a}$
}

Sr. Editor. El abuso en el consumo de alcohol desde la adolescencia genera consecuencias perjudiciales tanto físicas como mentales. Sin importar las restricciones legales, el consumo de alcohol en adolescentes es excesivo. En los últimos años se están utilizando vías alternas a la digestiva, usando para este fin otras cavidades y mucosas del organismo; además, la presión grupal tiene mucha influencia en estos jóvenes con ánimos de "experimentar", este fenómeno es conocido como binge drink. Las redes sociales han difundido de manera rápida estas prácticas denominadas "beber con el cuerpo", entre las cuales se tiene el eyeballing, los oxy shots, el "tampodka" o la "técnica de los cinco sentidos" (1).

El eyeballing consiste en introducir alcohol directamente a la mucosa ocular, el efecto alcohólico es mínimo porque evita la circulación, esta práctica está documentada en varios videos de YouTube, donde la curiosidad, las ganas de probar y la falta de preocupación son los denominadores comunes. A esto se le agrega el método de Oxy shot en la que se inhala alcohol con oxígeno en aerosol como si fuese un broncodilatador, consiguiendo una mayor absorción y una rápida acción, ya que evita el metabolismo hepático. Esta técnica es aprovechada por consumidores de cocaína porque libera las vías nasales por su efecto vasodilatador llamado "sniffeo de vodka". Esta práctica es realizada con el fin de experimentar y buscar la aceptación grupal, ellos mencionan: No hay un explicación lógica y motivo para hacer eso; lo único que genera es diversión en ver sufrir al que le toca hacerlo ${ }^{(2)}$.

Los ojos, la nariz y la boca no son las únicas vías de ingesta, a esto se le suma el "tampovodka" o el Tampax on the Rock que consiste en tampones embebidos

\footnotetext{
1 Facultad de Medicina, Universidad Nacional San Luis Gonzaga. Ica, Perú.

2 Sociedad Científica de Estudiantes de Medicina de Ica (SOCEMI).

a Estudiante de Medicina

Recibido: 18-08-15 Aprobado: 02-09-15
}

Citar como: Carrasco-Farfán CE, Quispe-Nolazco CM, Quispe-Nolazco centes [carta]. Rev Peru Med Exp Salud Publica. 2015;32(4):818-9. generalmente en vodka que se introducen por la vagina o el ano, permitiendo potenciar el impacto tóxico del alcohol, ya que evita el paso por el hígado y va directamente a la circulación sanguínea.

Investigaciones recientes sobre el uso alcohol por vía vaginal refieren que un $1,7 \%$ (17/1028) de las adolescentes encuestadas en la ciudad de Medellín, Colombia consumían alcohol por vía vaginal con efectos generales como borrachera o mareos y locales como prurito y ardor vulvovaginal (3).

El consumo de tequila en una técnica llamada "los cinco sentidos" consiste en "exprimir limón en los ojos, aspirar la sal y tomar el alcohol. Además de una bofetada, que involucra al tacto y finalmente gritar lo que incluye al oído". Si bien estas prácticas son muy dolorosas, en YouTube se encuentra más de 800 videos que muestran a jóvenes realizando estas técnicas ${ }^{(2)}$.

Al haber pocas publicaciones científicas sobre estas prácticas, los efectos clínicos no están bien determinados. Sin embargo, fisiopatológicamente tanto en el eyeballing como en el de "los cinco sentidos" existe el riesgo de daños corneales graves con eventual ceguera. De la misma manera, se podrían manifestar enfermedades pulmonares en el caso de los oxy-shots, e incrementar lesiones de mucosas e infecciones al realizar el "tampodka"(1).

Estas nuevas vías de administración originarias de Europa y Estados Unidos, ya se practican en países latinoamericanos como Colombia y México; en el Perú aún no hay reportes ni investigaciones sobre esta problemática, considerando que los adolescentes están expuestos a estas técnicas debido a la interacción cada vez mayor con las redes sociales ${ }^{(5)}$.

En la actualidad, los adolescentes consumen alcohol para sentirse bien, lograr la aceptación de un grupo social y perder la vergüenza de hacer cosas que en estado sobrio no harían. Las investigaciones señalan que el consumo de alcohol afecta las emociones, la personalidad, y las habilidades físicas y mentales donde está inmerso el uso de la memoria, y es en esta etapa de la adolescencia donde se facilita el consumo de alcohol y donde las nuevas vías de administración; perjudiciales para la salud; están tomando posición en países latinoamericanos.

\section{REFERENCIAS BIBLIOGRÁFICAS}

1. Burillo -Putze G., Hernandez-Sanchez MJ. Climent García B, Pinillos Echeverría MA. Nuevas formas de consumo de alcohol. Rev. An Pediatr (Barc). 2012;77(6):419-20. doi: 10.1016/j.anpedi.2012.03.017. 
2. Bousoño N. Un par de tequilazos para preparar la vista. prácticas de consumo de alcohol contemporáneo II. En: Libro de Resúmenes del VI Congreso Internacional de Investigación y Práctica Profesional en Psicología, XXI Jornadas de Investigación Décimo Encuentro de Investigadores en Psicología del MERCOSUR. Buenos Aires, Argentina. Facultad de Psicología, Universidad de Buenos Aires; 2014. p. 64-65.

3. Arango A, Vanegas CV. Efectos del consumo de alcohol vía vaginal en adolescentes en cuatro colegios de la ciudad de Medellín, Colombia. Rev Chil Obstet Ginecol. 2014;79(4):283-7.

4. Bousono N. Prácticas contemporáneas de consumo de alcohol: Una perspectiva psicoanalítica. Anu investig. 2012;19(2):57-62.

5. Monteiro Maristela G. Alcohol y salud pública en las Américas: un caso para la acción. Washington, D.C: OPS/OMS; 2007.

Correspondencia: Carlos Andrés Carrasco Farfán

Dirección: Los Pacaes A-29 Urb. San José. Ica, Perú.

Teléfono: (056) 969409456

Correo electrónico: candres.carrascof@gmail.com

\section{LA PLASTINACIÓN COMO MÉTODO DE CONSERVACIÓN DE TEJIDOS BIOLÓGICOS PARA DOCENCIA E INVESTIGACIÓN EN LA ANATOMÍA HUMANA}

\section{PLASTINATION AS A METHOD OF PRESERVATION OF BIOLOGICAL TISSUE FOR TEACHING AND RESEARCH IN HUMAN ANATOMY}

\section{Franklin Miranda Solis $1,2, a$}

Sr. Editor. En la formación de los médicos en nuestro país, la Anatomía es uno de los cursos más importantes de las ciencias básicas, la que se imparte en laboratorios especializados o anfiteatros. Estos lugares muchas veces son aulas adaptadas que no cuentan con un sistema de ventilación y menos con un sistema de

\footnotetext{
Facultad de Medicina, Universidad Nacional de San Antonio Abad del Cusco. Cusco, Perú.

2 Centro Nacional de Plastinación y Técnicas Anatómicas

aédico cirujano

Recibido: 22-08-15 Aprobado: 02-09-15
}

Citar como: Miranda Solis F. La plastinación como método de conservación de tejidos biológicos para docencia e investigación en la anatomía humana [carta]. Rev Peru Med Exp Salud Publica. 2015;32(4):819-20. conservación de órganos o cuerpos.

Antes de la invención del formaldehido como sustancia preservante los laboratorios implementaron técnicas y sustancias para la conservación de órganos y cadáveres tales como las resinas (aceites que retardaban el proceso de descomposición) (1). Estos agentes no llegan a conservar ciertas características como el color, volumen y otros aspectos que son importantes para el estudio y la investigación en esta área. Algunos agentes como el formaldehido presentan una elevada toxicidad, es así que en el año 2006 la Agencia Internacional para la Investigación sobre el Cáncer (IARC) lo clasificó como cancerígeno para los seres humanos ${ }^{(2)}$. Los laboratorios de Anatomía hacen uso de esta sustancia como agente fijador a

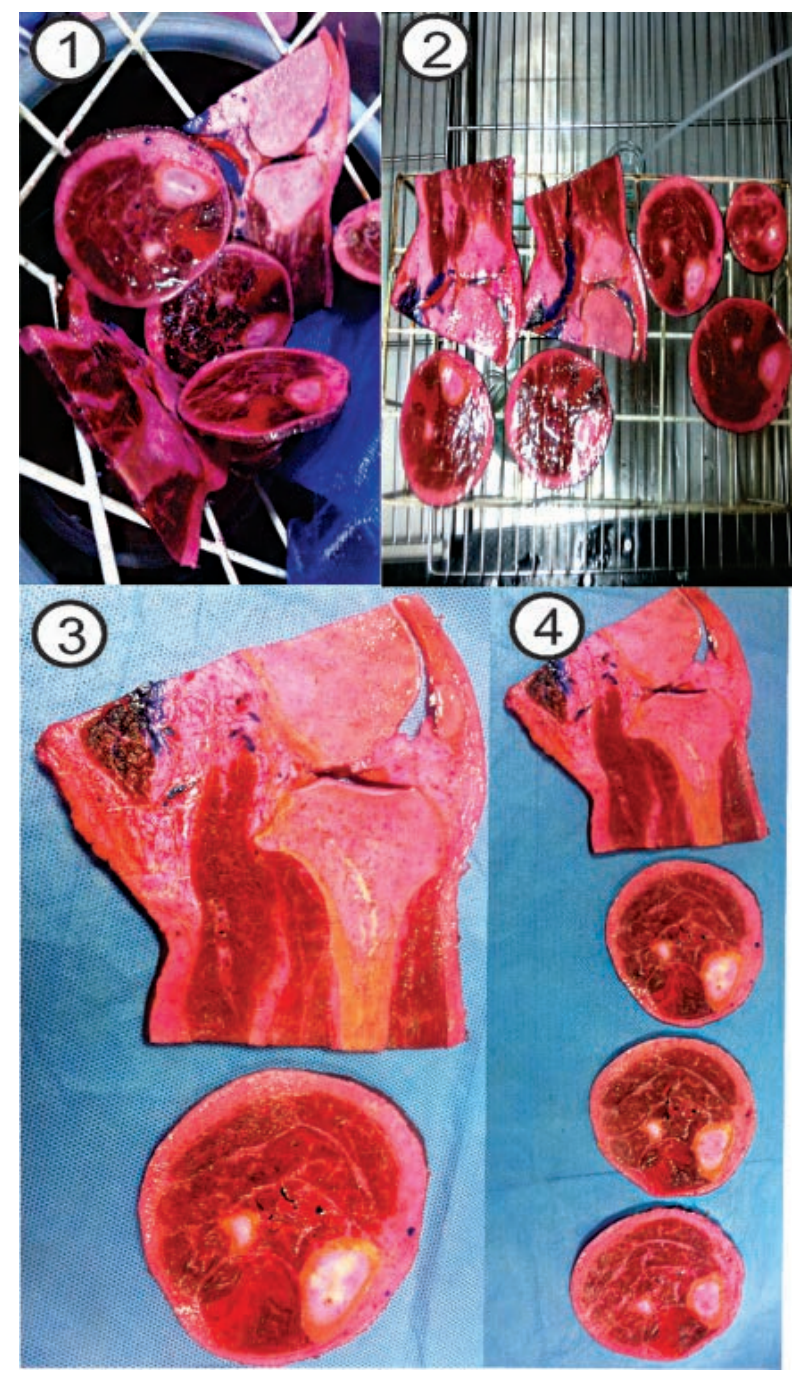

Figura 1. Se muestra secuencia de plastinación de corte de rodilla y tercio superior de pierna derecha: proceso final de impregnación forzada con silicona (1), para posteriormente pasar a cámara de curado con gas (2), quedando el producto final plastinado, libre de formol y de fácil manipulación (3 y 4). 